\title{
Letter to the editor regarding "Bone marrow lesion on magnetic resonance imaging indicates the last chance for hip osteonecrosis treated with vascularized fibular grafting before collapse"
}

\author{
Tomonori Shigemura $^{1}$ (D) Yuki Shiratani ${ }^{1} \cdot$ Hiroyuki Hamano $^{1}$ \\ Received: 28 July 2020 / Accepted: 4 August 2020 / Published online: 12 August 2020 \\ (C) SICOT aisbl 2020
}

We read with great interest the article titled "Bone marrow lesion on magnetic resonance imaging indicates the last chance for hip osteonecrosis treated with vascularized fibular grafting before collapse" by Huang et al. and would like to congratulate the authors for their study [1]. The authors conducted a retrospective cohort study to evaluate whether the noncollapsed hips with bone marrow lesion (BML) can benefit from free vascularized fibular grafting (FVFG), and concluded that BML indicates the last chance for a reproducible improvement in the treatment of hip osteonecrosis with FVFG before collapse.

Although they have touched a highly pertinent topic in a scientific manner, the study has brought a serious issue which may confuse the readers. We would like to point this out, because International Orthopaedics is a very influential journal for many readers.

The authors used the word BML as a synonym for bone marrow edema (BME). Both are findings of magnetic resonance imaging; however, the two are completely different. BME is diffuse signal abnormality in the marrow of the femoral head and neck, which extends into the intertrochanteric area. BME is found in collapsed osteonecrosis of femoral head, and correlated to pain $[2,3]$.

On the other hand, BML is frequently detected in joints with osteoarthritis (OA), and clinically associated with joint pain, cartilage volume loss, and structural changes. Shabestari et al. demonstrated increased bone turnover and angiogenesis in BML of hip OA [4].

Tomonori Shigemura

tshigepon@yahoo.co.jp

1 Department of Orthopaedic Surgery, Teikyo University Chiba Medical Center, 3426-3 Anesaki, Ichihara, Chiba 299-0111, Japan
As shown above, the two words have completely different meanings, so we think it is better to distinguish them clearly.

\section{Compliance with ethical standards}

Conflict of interest The authors declare that they have no conflict of interest.

\section{References}

1. Huang YG, Chia WK, Jin D, Gao Y, Sheng J, Zhang C (2020) Bone marrow lesion on magnetic resonance imaging indicates the last chance for hip osteonecrosis treated with vascularized fibular grafting before collapse. Int Orthop. https://doi.org/10.1007/ s00264-020-04697-5

2. Iida S, Harada Y, Shimizu K, Sakamoto M, Ikenoue S, Akita T, Kitahara H, Moriya H (2000) Correlation between bone marrow edema and collapse of the femoral head in steroid-induced osteonecrosis. AJR Am J Roentgenol 174:735-743. https://doi.org/ 10.2214/ajr.174.3.1740735

3. Hatanaka H, Motomura G, Ikemura S, Kubo Y, Utsunomiya T, Baba S, Kawano K, Nakashima Y (2019) Differences in magnetic resonance findings between symptomatic and asymptomatic pre-collapse osteonecrosis of the femoral head. Eur J Radiol 112:1-6. https://doi. org/10.1016/j.ejrad.2019.01.002

4. Shabestari M, Vik J, Reseland JE, Eriksen EF (2016) Bone marrow lesions in hip osteoarthritis are characterized by increased bone turnover and enhanced angiogenesis. Osteoarthr Cartil 24:1745-1752. https://doi.org/10.1016/j.joca.2016.05.009

Publisher's note Springer Nature remains neutral with regard to jurisdictional claims in published maps and institutional affiliations. 